\title{
Distinct song parts of the endemic marsh grassbird of China vary with latitude and climate among migratory and sedentary populations
}

\author{
Xiaoying Xing ${ }^{1} \cdot$ Hans Slabbekoorn ${ }^{2} \cdot$ James Campbell $^{2} \cdot$ \\ Feng $\mathrm{Li}^{1} \cdot$ Jianzhang $\mathrm{Ma}^{1}$ (D)
}

Received: 6 July 2016/Accepted: 29 November 2016/Published online: 4 January 2017

(C) The Author(s) 2017. This article is published with open access at Springerlink.com

\begin{abstract}
Birdsong can act as a premating barrier to gene flow through its role in mate attraction and territorial defence. The link between geographic variation in song structure and ecological factors is key to the process of acoustically guided population divergence and isolation. Migratory behaviour is an example of such an ecological factor. In this study, we asked whether latitude and climate can explain song variation among migratory and sedentary populations of the marsh grassbird (Locustella pryeri sinensis), a rare songbird endemic of wetlands of eastern and northeastern China. We investigated two structurally different song parts: a repeating trill part followed by a more variable warble part. We found significant variation in acoustic structure and distinct divergence patterns between the two song parts across a latitudinal gradient and strong acoustic correlations with several bioclimatic variables. The trill part showed an increase in maximum frequency with latitude and the warble part became longer with fewer element types towards three higher latitude, migratory populations. These patterns are in line with a dual function of both song parts, increased sexual selection pressure at higher latitude and a complex impact of climate on song through vegetation and weather conditions.
\end{abstract}

Keywords Birdsong divergence $\cdot$ Bird migration $\cdot$ Latitudinal gradient $\cdot$ Locustella pryeri sinensis $\cdot$ Meme flow · WorldClim

Electronic supplementary material The online version of this article (doi:10.1007/s10682-016-9879-7) contains supplementary material, which is available to authorized users.

Feng Li

birdpaper@163.com

$\bowtie$ Jianzhang Ma

1 College of Wildlife Resource, Northeast Forestry University, No. 26 Hexing Road, Xiangfang District, Harbin 150040, People's Republic of China

2 Institute of Biology, Leiden University, 2300 Leiden, The Netherlands 


\section{Introduction}

Geographic variation in birdsong can affect gene flow among populations and play an important role in avian speciation (Slabbekoorn and Smith 2002; Edwards et al. 2005; Price 2008). Song variation and associated acoustic response patterns by potential mates and competitors are well-accepted as descriptors of species boundaries and key factors in intra-specific population divergence. Therefore, understanding the causes and consequences of song divergence among populations of the same species has great potential to yield insight into the evolutionary emergence of restrictions on gene flow through songdependent success in territory establishment and mate attraction (e.g. Irwin 2000; Danner et al. 2011; Kleindorfer et al. 2013; Greig et al. 2015).

Acoustic variation among different populations of the same bird species may arise through different processes (Ellers and Slabbekoorn 2003; Kroodsma 2004; Podos and Warren 2007). Dispersal to established or new populations may cause founder effects for vocal memes through drift and mutation processes (Lachlan et al. 2013). Many species have the ability of vocal learning (Slater 1986; Hultsch and Todt 2004; Beecher and Brenowitz 2005) and song sharing among neighbours and emergence of novel variation through copy errors may yield patterns of local convergence and geographic divergence (e.g. Ellers and Slabbekoorn 2003). Furthermore, song evolution may be shaped by morphological and physical constraints (Podos and Nowicki 2004) as well as environmental conditions (Boncoraglio and Saino 2007; Ey and Fischer 2009).

Migratory behaviour is another important ecological factor which has been related to patterns of geographic variation in birdsong and speciation (Mortega et al. 2014; Rolland et al. 2014). Some studies have suggested that migratory populations have evolved more divergent songs through improvisation and more elaborated songs because they are under stronger sexual selection due to a short breeding season (Catchpole 1982; Collins et al. 2009). Sedentary populations may also have more convergent songs through copying of neighbourhood songs, at least in some species, driven by the higher consistency in the identity of neighbouring males (Kroodsma 1999). Furthermore, variation in habitat density and species diversity may yield variable competition for acoustic space, and thereby allow song elaboration more easily at relatively high latitudes, where vegetation is typically less dense and acoustic competition with other species less intense (Weir and Wheatcroft 2011; Singh et al. 2015). Several comparative studies have confirmed positive correlations between song elaboration and latitude, both among (Catchpole 1982; Botero et al. 2009) and within species (Collins et al. 2009; Kaluthota et al. 2016). However, there are also studies with contrasting results (Byers 2011, 2015; Medina and Francis 2012) and more studies are needed for a better understanding.

Song variation linked to migratory tendency may affect the probability of gene flow between populations at different latitudes (Collins et al. 2009; Mortega et al. 2014; Gordinho et al. 2015). Populations breeding at different latitude may be spatially and temporally segregated in terms of vocal activity and perceptual windows for vocal learning. Consequently, a pattern of isolation by distance in geographic song variation is likely to emerge through both individual dispersal and song learning processes, which opens up potential for acoustically guided population divergence (Ellers and Slabbekoorn 2003; Podos and Warren 2007). This may be especially the case if such variation is linked to a heritable trait of ecological relevance such as migratory tendency (Winker 2000; Slabbekoorn and Smith 2002; Rolland et al. 2014). Species confined to fragmented habitats may be a special case in this respect as they occur in separated populations in habitat 
islands (c.f. Baker 1996; Slabbekoorn et al. 2003), which induces potentially discrete and concordant steps in variation for both acoustic traits and migratory tendency.

The marsh grassbird (Locustella pryeri Seebohm) provides a suitable case for investigating divergent and convergent influences on bird song variation. It is range limited to wetland habitats and categorized as 'Near Threatened' (BirdLife International 2012). Seven island populations have been identified for the sinensis subspecies in China (Fig. 1a), which is a partial migrant with birds from the three northern populations being migratory while the four more southern populations being sedentary (Li and Wang 2006; Zhang 2011; Hou 2014). Marsh grassbirds are typically cryptic, except for during the breeding season, from April to July (Madge 2006), when they exhibit a stereotypic song

(a)

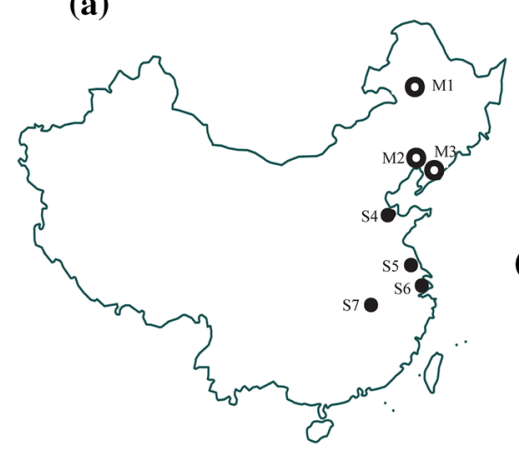

(b)

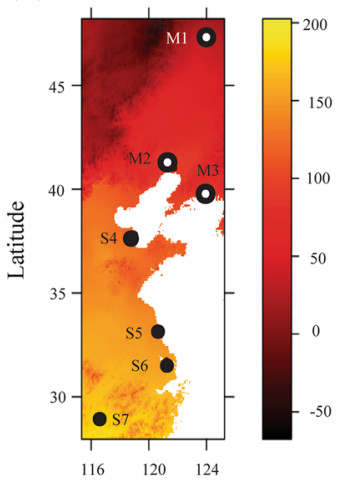

(d) bio 12 Annual precipitation

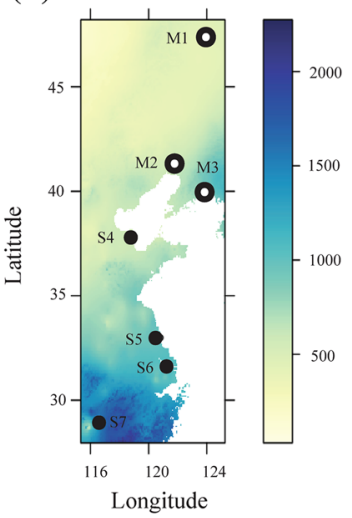

(c)

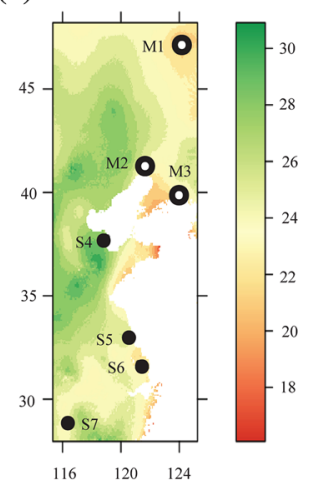

(e) bio 15 Precipitation seasonality

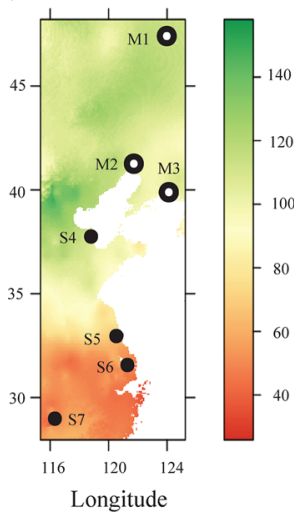

Fig. 1 Four bioclimatic maps of the eastern and north-eastern part of China. a The map of China with the locations of all seven wetland localities of the marsh grassbird study populations. White dots of M1-3 indicate fully migratory populations in the north, and black dots of S4-7 indicate sedentary populations in the south. We provide information on 4 of the 19 bioclimatic variables (see Table 2) from the WorldClim database (http://www.worldclim.org/current, based on average monthly climate data collected between 1950 and 1990, interpolated globally at a resolution of 30 arc-seconds (Hijmans et al. 2005). b Annual mean temperature (bio 01 ) in ${ }^{\circ} \mathrm{C}^{*} 10$ (The WorldClim database multiplies their ${ }^{\circ} \mathrm{C}$ values by 10 for computational reasons); $\mathbf{c}$ isothermality (bio 03), which is the mean diurnal range (bio 02) divided by the annual temperature range (bio 07); $\mathbf{d}$ annual precipitation (bio 12) in $\mathrm{mm}$; and $\mathbf{e}$ precipitation seasonality (bio 15) 
comprised of a repeating trill while perched, followed by a variable warble that is sung during a distinct flight display (Qu et al. 2011).

In this study, we provide a first description of geographic variation in the two structurally different parts of marsh grassbird song. We first quantified the structural differences in these two song parts, and further tested whether song variation was correlated with latitude and bioclimatic variables. We included rainfall and temperature, which are well-known to affect migratory behaviour (Salewski and Bruderer 2007; Louchart 2008; Zink 2011) and possibly song structure (e.g. Botero et al. 2009; Weir and Wheatcroft 2011; Medina and Francis 2012). We explored whether the acoustic variation within songs and across latitude and climate was in line with expectations for divergent functions of the different song parts. We expected to confirm anecdotal field observations suggesting that the opening trill would consist of more simple and repetitive elements relative to the variable warble. Furthermore, especially for the warble, we expected a pattern of song elaboration with latitude and stronger seasonal fluctuations in climatological conditions in the north, which are correlated with longer migratory distances, shorter breeding seasons and stronger sexual selection pressures.

\section{Materials and methods}

\section{Song recording and measurements}

We recorded songs during the breeding season (April-July) by multiple observers between the years of 2008 and 2014, from 6 to 11 A.M. (see Fig. 1; Table 1 for recording localities), using a Roland R-44 digital recorder (Roland China Limited, Beijing, China) and a Sennheiser MKH 416 directional microphone (Sennheiser Electronic Co. Ltd, Beijing, China) using a sample rate of $44.1 \mathrm{kHz}$. Male grassbirds are strongly territorial and show high local site fidelity, which makes it likely that recordings at different territories are also from different males (which were not banded). In a previous study, we have shown that each male grassbird has a unique song with a combination of many different element types that are sung in more or less repetitive series (Qu et al. 2011). Each song contains two distinct parts: a trill (referred to as part a in this study), consisting of a long series of elements sung in repetitive fashion, followed by a warble (referred to as part b), a long series of elements that are more complex and that are sung in highly variable sequences

Table 1 Recording information of localities and individuals

\begin{tabular}{llllll}
\hline Population & Location & Latitude & Longitude & $\begin{array}{l}\text { Number of individuals } \\
\text { recorded }\end{array}$ & $\begin{array}{l}\text { Number of songs } \\
\text { analyzed }\end{array}$ \\
\hline M1 & Zhalong & $47^{\circ} 11^{\prime} 42^{\prime \prime}$ & $124^{\circ} 14^{\prime} 4^{\prime \prime}$ & 12 & 49 \\
M2 & Shuangtaihe & $41^{\circ} 1^{\prime} 49^{\prime \prime}$ & $121^{\circ} 44^{\prime} 45^{\prime \prime}$ & 15 & 50 \\
M3 & Dandong & $39^{\circ} 52^{\prime} 57^{\prime \prime}$ & $123^{\circ} 37^{\prime} 43^{\prime \prime}$ & 15 & 72 \\
S4 & Dongying & $37^{\circ} 48^{\prime} 51^{\prime \prime}$ & $119^{\circ} 2^{\prime} 17^{\prime \prime}$ & 12 & 57 \\
S5 & Dafeng & $32^{\circ} 59^{\prime} 35^{\prime \prime}$ & $120^{\circ} 48^{\prime} 42^{\prime \prime}$ & 15 & 68 \\
S6 & Chongming & $31^{\circ} 43^{\prime} 43^{\prime \prime}$ & $121^{\circ} 13^{\prime} 37^{\prime \prime}$ & 16 & 72 \\
S7 & Nanjishan & $28^{\circ} 56^{\prime} 54^{\prime \prime}$ & $116^{\circ} 21^{\prime} 12^{\prime \prime}$ & 16 & 53 \\
Total & & & & 101 & 421 \\
\hline
\end{tabular}

Population codes have an $\mathrm{M}$ when they are migratory and an $\mathrm{S}$ when sedentary combined with a unique identifying number. All these seven recording sites are wetlands of nature reserves in China 
with only few repeats and typically different element types for every subsequent element in the string (Fig. 2). Observations in the field and video recordings indicate that the transition from simple and repetitive to more variable warble typically follows soon after shifting from perched song to a song display flight.

We chose about five songs of high recording quality from each individual for measurements and analyses. We processed the following three temporal parameters (Fig. 2): song part duration ( $\mathrm{D}$, time from start of the first element to end of the last element), number of element types (NT, variety in distinct element shape other than appearance shifts related to relative amplitude), and element rate ( $R$, number of elements sung per second). We also processed three spectral parameters: maximum $\left(\mathrm{F}_{\max }\right.$, upper limit of the visible sound trace on the spectrogram of any song element within the target song part), minimum $\left(\mathrm{F}_{\mathrm{min}}\right.$, lower limit of the visible sound trace on the spectrogram of any song element within the target song part) and peak frequency ( $\mathrm{F}_{\text {peak }}$, frequency of highest amplitude for the accumulated energy over all elements within the target song part). We measured the frequency parameters through visual inspection of sonograms, always generated using the very same settings in Avisoft. Although there are better-standardized ways to measure spectral parameters (see e.g. Zollinger et al. 2012; Cardoso and Atwell 2012), we are confident of consistent and objective cursor placement at upper and lower edges of sound traces attributed to birdsong for $\mathrm{F}_{\max }$ and $\mathrm{F}_{\min }$. Furthermore, we believe there is no potential for measurement bias that can explain any of the patterns of spectral variation between song parts within songs or among songs of different sites.

All acoustic measurements were done using Avisoft-SAS Lab Pro 4.52 software (Avisoft Bioacoustics, Berlin, Germany), with a sampling rate of $22.05 \mathrm{kHz}$. We made spectrograms with a frequency resolution of $86 \mathrm{~Hz}$ and a temporal resolution of $1.45 \mathrm{~ms}$ (spectrogram settings: Window: Flat Top window, overlap: 75\%, window length: 256). Spectrograms of different song recordings were normalized with respect to their maximum amplitude and all parameters were measured separately for both the trill and the warble part of the song (the footnotes a or $b$ were used to label trill and warble, respectively).

\section{Statistical analyses and bioclimatic variables}

To examine the structural differences between parts a and $b$ of the recorded songs (see Fig. 2), we first tested the measured acoustic parameters for normality using a

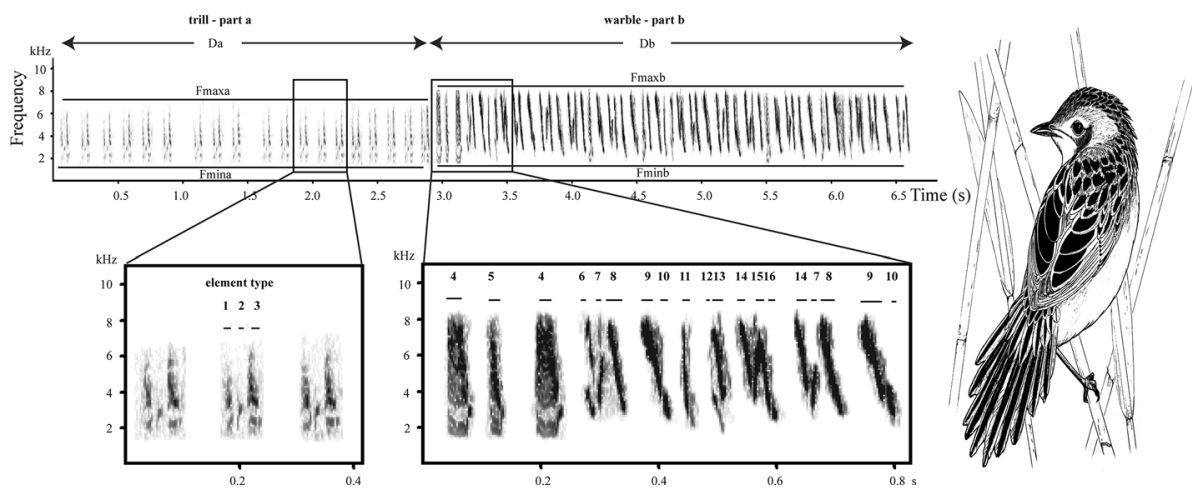

Fig. 2 Spectrograms of a typical song of the marsh grasswarbler Locustella pryeri sinensis showing the two song parts, how we assigned elements to different types and how the parameters were measured in this study 
Kolmogorov-Smirnov test and subsequently used either a paired $T$ test or a Wilcoxon signed-ranks test to assess whether acoustic differences between the repeating trill part and variable warble part were significant (SPSS 16.0, SPSS Inc., Chicago, IL, USA). We then applied a linear mixed-effects model ( $\mathrm{R}$ version 3.2.3, package lme4) to examine the correlation between song characteristics, latitude, and whether or not the population was migratory, in addition to 19 bioclimatic variables (Table 2) from the WorldClim database (http://www.worldclim.org/current, 2.5 decimal degree resolution).

The WorldClim database is widely used in species distribution modelling (De Clercq et al. 2015) and is composed of average monthly climate data collected between 1950 and 1990, interpolated globally at a resolution of 30 arc-seconds (Hijmans et al. 2005). We defined the random effect of our models as the population subgroup (random intercept, 7 groups) and the best fitting model for each song characteristic was selected using AIC stepwise selection (forward direction), where a model with an AIC score two points lower than another was considered a significantly better fit (Burnham and Anderson 2003). Song characteristics which expressed a skewed distribution were logtransformed to meet the assumptions of normally distributed residuals (Da, NTa, and Fmaxa, see also Table 3).

We then compared our final models to a latitude only model (where latitude was the only fixed effect) and null model (with no fixed effects), and used the AIC score to determine if the final models were significantly better fitting than the alternative latitude and null models. We also calculated the marginal $\mathrm{R}^{2}$ values for our models as described in Nakagawa et al. (2013) using the package MuMIn. Finally, a Spearman correlation matrix was calculated to examine the colinearity between the bioclimatic variables and latitude (see Appendix S1 in Supporting Information).

Table 2 Descriptions of the WorldClim bioclimatic variables used in the mixed model analysis

\begin{tabular}{ll}
\hline Bioclim code & Description \\
\hline Bio 01 & Annual mean temperature \\
Bio 02 & Mean diurnal range \\
Bio 03 & Isothermality \\
Bio 04 & Temperature seasonality \\
Bio 05 & Max temperature of warmest month \\
Bio 06 & Min temperature of coldest month \\
Bio 07 & Temperature annual range \\
Bio 08 & Mean temperature of wettest quarter \\
Bio 09 & Mean temperature of driest quarter \\
Bio 10 & Mean temperature of warmest quarter \\
Bio 11 & Mean temperature of coldest quarter \\
Bio 12 & Annual precipitation \\
Bio 13 & Precipitation of wettest month \\
Bio 14 & Precipitation of driest month \\
Bio 15 & Precipitation seasonality \\
Bio 16 & Precipitation of wettest quarter \\
Bio 17 & Precipitation of driest quarter \\
Bio 18 & Precipitation of warmest quarter \\
Bio 19 & Precipitation of coldest quarter \\
\hline &
\end{tabular}


Table 3 Summarized results from the mixed model analysis of song characteristics. The best fitting model for each song characteristic was selected using AIC stepwise selection where a model with an AIC score two points lower than another was considered a significantly better fit

\begin{tabular}{|c|c|c|c|c|c|c|}
\hline \multirow[t]{2}{*}{ Characteristic } & \multirow[t]{2}{*}{ Fixed effects } & \multicolumn{2}{|c|}{ Final model } & \multicolumn{2}{|c|}{ Latitude model } & \multirow{2}{*}{$\begin{array}{l}\text { Null model } \\
\text { AIC }\end{array}$} \\
\hline & & AIC & $\mathrm{R}_{\mathrm{m}}^{2}$ & AIC & $\mathrm{R}_{\mathrm{m}}^{2}$ & \\
\hline $\mathrm{Da}^{\mathrm{c}}$ & bio_8 & $207.33^{b}$ & 0.080 & 212.68 & 0.013 & 211.36 \\
\hline $\mathrm{Db}$ & bio_15bio_12 & $209.88^{b}$ & 0.206 & $216.95^{\mathrm{a}}$ & 0.100 & 218.95 \\
\hline $\mathrm{NTa}^{\mathrm{c}}$ & bio_13 & $117.23^{\mathrm{b}}$ & 0.071 & 121.46 & 0.031 & 122.46 \\
\hline $\mathrm{NTb}$ & bio_10 & 558.50 & 0.219 & $559.45^{\mathrm{a}}$ & 0.212 & 570.13 \\
\hline Fmaxa $^{c}$ & bio_4 & -180.41 & 0.081 & $-179.47^{\mathrm{a}}$ & 0.072 & -175.81 \\
\hline Fmaxb & bio_3 & $1400.86^{b}$ & 0.299 & 1418.55 & 0.041 & 1417.49 \\
\hline
\end{tabular}

$\mathrm{R}_{\mathrm{m}}^{2}$ represents the marginal $\mathrm{R}^{2}$ which can be interpreted as the proportion of variance explained exclusively by the fixed effects of the model

${ }^{a}$ The latitude model is a significantly better fit than the null model for that song characteristic, (i.e. it has an AIC score at least 2 points lower)

b The final model is a significantly better fit than both the Null and Latitude models

${ }^{c}$ Log transformed to preserve the normal distribution of residuals

\section{Results}

\section{Comparisons between two different song parts}

The trill part of the song was typically sung while perched and preceding a contiguous transition into the warble part in display flight. The two song parts differed significantly in the trill part being shorter $(t=-4.11, P<0.001)$, having fewer element types ( $t=-48.22, P<0.001)$, a lower maximum frequency $(t=-27.70, P<0.001)$, a lower peak frequency $(t=-19.50, P<0.001)$, and a higher element rate $(t=4.40, P<0.001)$ than the warble part (see Fig. 3 and Appendix S2). The minimum frequency exhibited no significant variation among the two song parts $(Z=91.00, \mathrm{NS})$.

\section{Song differentiation with latitude and climate}

We found several significant correlations between song variation, latitude, and bioclimatic variables (Figs. 1, 3). The results of the analyses are summarized in Appendix S2. When comparing our latitude models to our null models, the distribution of Fmax (Fig. 3e) across populations was explained best by the latitude model, with higher trill frequencies towards the North. $\mathrm{D}_{\mathrm{b}}$ (Fig. 3b) and $\mathrm{NT}_{\mathrm{b}}$ (Fig. 3d) were also explained best by the bioclimatic and latitude model respectively, with longer warble parts but fewer warble element types towards the North. The addition of a fixed effect classifying populations as either migratory or sedentary did not significantly improve the AIC score of any of the models predicting the spatial distribution of song characteristics.

While the models for all song characteristics which included the bioclimatic variables performed better than their null model equivalents, only the bioclimatic models for $\mathrm{D}_{\mathrm{a}}$ (Fig. 3a), $\mathrm{D}_{\mathrm{b}}$ (Fig. 3b), NT (Fig. 3c), and $\mathrm{Fmax}_{\mathrm{b}}$ (Fig. 3f) resulted in significantly better fitting models as compared to the alternative models using latitude alone as a fixed effect. According to the AIC stepwise selection, the selected predictors which resulted in the best 
10 (a)
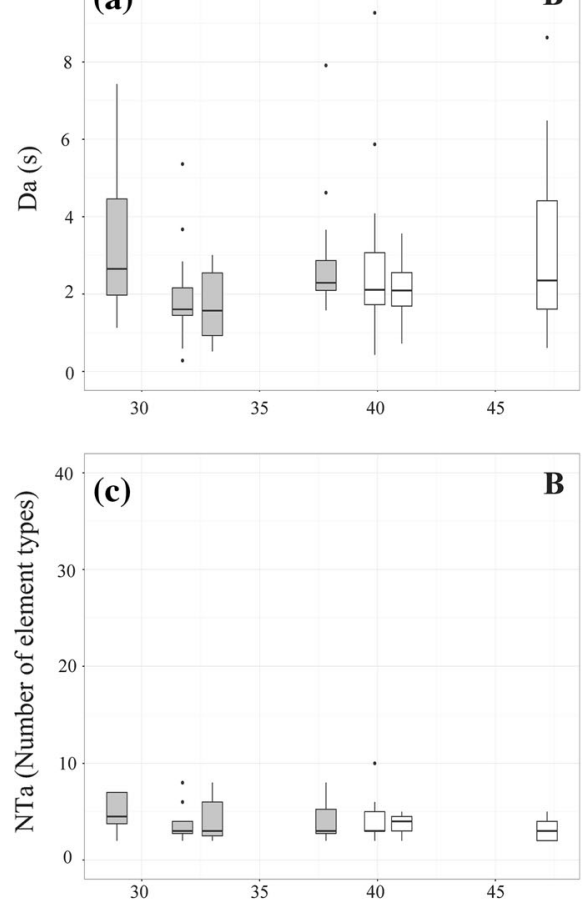

${ }^{10} \cdot$ (e)

$\mathbf{L}$

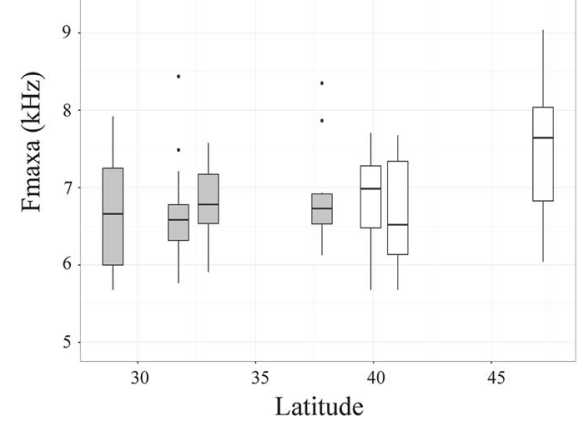

10 (b)

B
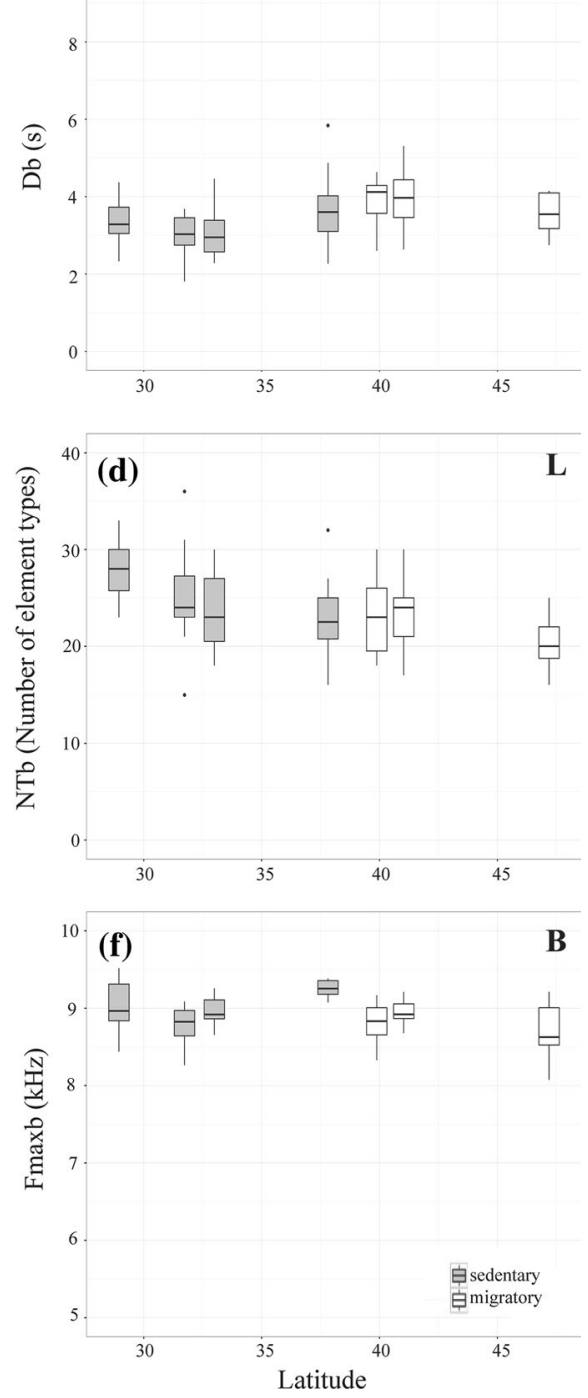

Fig. 3 Box-whisker plots of 6 acoustic parameters showing divergences among the 7 island populations of the marsh grassbird. Populations are listed from left to right with increasing latitude (from south to north). Mixed models were employed to examine the relationship between the acoustic parameters of each population and their associated latitude and bioclimatic values. A ' $\mathrm{B}$ ' in the upper right corner of a plot indicates that the model using only bioclimatic variables as its fixed effects provided the best fit while an ' $\mathrm{L}$ ' indicates that the model using latitude alone provided the best fit. Null models with no fixed effects were also tested, but did not provide the best fit for any of the parameters

fitting model for these four song parameters were, respectively: mean temperature of wettest quarter (bio_8), precipitation seasonality (bio_15, Fig. 1e) and the combination of annual precipitation (bio_12, Fig. 1d), precipitation of the wettest month (bio_13), and isothermality (bio_3, Fig. 1c; Table 3). 


\section{Discussion}

We successfully assessed geographic variation in two distinct parts of the marsh grassbird song in all seven populations known for the species in eastern and north-eastern China. The trill and warble parts differed significantly in several parameters and we found significant correlations between song variation in both the trill and the warble with latitude and bioclimatic variables. The trill was shorter than the warble, had far less variety in terms of the number of different element types, and covered a smaller frequency range, expressed in a lower maximum frequency. The trill increased in maximum frequency towards the north, while the warble increased in duration and decreased in the number of different element types with increasing latitude. Bioclimatic variables varied sufficiently independent from latitude to significantly improve the explanatory value of our statistical models.

\section{Sexual selection and within-song divergence}

We found large and consistent differences between the two parts of the marsh grassbird songs that are very much in line with the expectations for at least some functional subdivision. The trill part is shorter, less diverse and covers a more narrow frequency range than the warble part, which is in line with a functional bias towards male-male interactions for the repeating trill and towards male-female interactions for the variable warble (Catchpole 1982; Collins 2004). The trill part can also be sung by itself and seems the default, relatively low-effort advertisement signal while being perched somewhere within the territory boundaries. The fact that the transition towards the more complex part coincides with the energy-demanding ascending stage of the flight display also argues for display elaboration driven by sexual selection in the context of female mate attraction. However, it remains very difficult to conclusively attribute specific functions or targeted receivers to the different song parts as typically both song parts are present in most songs and also both sexes may be among the potential audience.

Changes in song use through the course of the season or after obtaining or losing a mate have often been taken as evidence for a functional subdivision of different song parts (e.g. Fessl and Hoi 1996; Beckett and Ritchison 2010). For example, blackcaps, Sylvia atricapilla, start their song with a complex warble part of wide bandwidth followed by a whistle part with louder and pure fluting tones of narrower bandwidth. The warble part becomes shorter as the breeding season progresses and is hardly sung at all after egg laying has finished (Collins et al. 2009). Furthermore, the whistle becomes more prominent in length relative to the warble during male-male interactions and playback (Leedale et al. 2015; Linossier et al. 2015). In the chaffinch, Fringilla coelebs, males start their song with a sequence of a few different trills followed by an unrepeated flourish. Indoor playbacks revealed that captive female chaffinches have a preference for a relatively longer flourish (Riebel and Slater 1998), while outdoor playbacks have shown that territorial males responded strongest when the trill part was relatively longer (Leitão and Riebel 2003).

Although these observational patterns of song use and response patterns to playback of variation are suggestive for a functional subdivision with respect to the dual function of song, the most convincing evidence for a sex-dependent message in two different song parts would be the induction of a shift in a singing male upon exposure to a male or female conspecific. For the marsh grassbird, we have no insights yet into seasonal changes or response patterns to playback. However, we report a consistent use of two song parts across seven populations and argue that it 
would be very interesting to investigate seasonal variation in the relative duration of both parts and their responses to the playback of these two parts.

\section{Complex divergence patterns across latitude}

We found several significant acoustic correlations with latitude; some of which as expected others hard to explain. The duration of the warble part was positively correlated with latitude, which is in line with expected elaboration in more seasonal and unpredictable habitat with presumable stronger sexual selection pressures (c.f. Catchpole 1982; Irwin 2000; Botero et al. 2009; Weir and Wheatcroft 2011). However, at the same time we found the number of different element types of the warble part to be negatively correlated with latitude. This was not congruent with elaboration in duration and not in line with the variation in selection pressures expected from the ecologically divergent conditions for the sedentary populations in the south and the migratory populations in the north. Consequently, the marsh grassbird contributes another case of contradictory patterns to the literature and confirms that there are no simple explanations or clear general patterns (c.f. Byers 2011, 2015; Medina and Francis 2012).

Although there is a clear lack of congruency between the geographic patterns in duration and element diversity, there are still strong patterns that call for an explanation. The fact that both correlations were found in the variable warble and not in the repeating trill confirms that different song parts with apparent functional differences can evolve more or less independently (c.f. Kroodsma 1981; Baker 2011). A recent study on different subspecies of the reed bunting (Emberiza schoeniclus) in Europe provided another similar case for a species of wetland island populations (Gordinho et al. 2015). In that study, latitudinal divergence in song complexity was also opposite of what would be expected.

However, follow-up studies are needed to gain more insights into functional differences between song parts and possibly divergent selection pressures on specific acoustic features. Investigations of correlations between parameters at the individual level and across the season may reveal internal coherence and functional significance. Playback experiments in marsh grassbirds, in which duration and element diversity are manipulated independently may be another tool that could yield critical insights for a better understanding of the interplay between sexual selection, acoustic and population divergence.

\section{Song variation and climate}

Our analyses of geographic variation of grassbird song also revealed a strong explanatory power for several bioclimatic variables. Latitude will partly explain climatological conditions, but they are modified by geographic factors such as, for example, proximity to the coast, altitudinal variation, prominent directions of ocean currents and wind. Furthermore, latitude likely has a more important additional value to just local climate for species that cover a large geographic area for dispersal and migration.

The impact of bioclimatic variables on birdsong has been reported before (Botero et al. 2009), and can be driven by effects of precipitation and temperature on vegetation, food availability and the consequences for sexual selection. Rainfall patterns and temperature fluctuations determine, for example, reed growth (Garris et al. 2015) and food availability (Gwitira et al. 2015) and thereby affect distribution, density, spring arrival dates and breeding success of reed bird communities (e.g. Virkkala et al. 2005; Halupka et al. 2008; Eglington et al. 2015). 
Although a more variable and unpredictable climate has been related to more elaborate songs (Botero et al. 2009), it remains hard to directly explain why a variable such as isothermality matches strongly with maximum song frequency, as found for the warble part of the marsh grassbird. However, it should be no surprise that climate and latitude together may better predict variation in sexual selection pressures related to variable and unpredictable climate (Irwin 2000; Botero et al. 2009). The correlation between spectral bandwidth and latitude may also be attributed to habitat structure and community composition: selection against using higher frequencies may be relaxed because of more open vegetation and less competition for acoustic space due to fewer vocally active sympatric species in the north (Weir et al. 2012; Singh et al. 2015). Although community richness of vocal bird species and relative habitat openness in our seven populations may vary along the lines of these published studies, such measurements are not yet available and await future studies.

Propagation effects of vegetation on song transmission and the phenomenon of habitatdependent song variation have been reported especially for forest habitat (Slabbekoorn 2004; Ey and Fischer 2009), but also reed stalks are known to filter selectively and provide better propagation conditions for low than for high song frequencies (Cosens and Falls 1984). An important fact may be that the warble is sung in flight and may be largely free of excess attenuation, but that the trill is predominantly sung perched and may have a transmission pathway to potential receivers through dense vegetation. However, currently we have no access to environmental data of the required detail for the marsh grassbird and further progress in our understanding depends on future sampling efforts.

\section{Conclusions}

Our acoustic description of vocal behaviour of marsh grassbirds across three migratory and four sedentary populations in China is in line with the expectations for a functional subdivision between the different parts of their songs. We also found interesting but not always congruent acoustic correlations with latitude and climate that may be related to variation in sexual selection pressures and migratory behaviour. However, a better understanding requires experimental studies into functional differentiation and possible seasonal and geographical variation as well as acoustic exploration of latitudinal variation in vegetation density and sound propagation. The discrete nature of the seven populations of this rare and endemic Chinese subspecies makes the marsh grassbird highly suitable for such studies addressing the interplay between birdsong, migration and speciation. Furthermore, conservation concern also makes them worthwhile to investigate as they feature on the IUCN red list and the kind of wetland areas they inhabit are globally threatened (Quesnelle et al. 2013).

Acknowledgements We thank Katharina Riebel very much for her useful comments on an earlier version of our manuscript. Thanks also to Lucia Berti for drawing the Locustella pryeri in Fig. 2. We also thank two anonymous reviewers for constructive feedback that allowed us to improve the paper. This study was supported by Fundamental Research Funds for the Central Universities of China 2572016CA09 and the National Natural Science Foundation of China 31501867/30770309/31071940.

Open Access This article is distributed under the terms of the Creative Commons Attribution 4.0 International License (http://creativecommons.org/licenses/by/4.0/), which permits unrestricted use, distribution, and reproduction in any medium, provided you give appropriate credit to the original author(s) and the source, provide a link to the Creative Commons license, and indicate if changes were made. 


\section{References}

Baker MC (1996) Depauperate meme pool of vocal signals in an island population of singing honeyeaters. Anim Behav 51:853-858

Baker MC (2011) Geographic variation of three vocal signals in the Australian ringneck (Aves: Psittaciformes): do functionally similar signals have similar spatial distributions? Behaviour 148:373-402

Beckett MD, Ritchison G (2010) Effects of breeding stage and behavioral context on singing behavior of male indigo buntings. Wilson J Ornithol 122:655-665

Beecher MD, Brenowitz EA (2005) Functional aspects of song learning in songbirds. Trends Ecol Evol 20:143-149

BirdLife International (2012) Locustella pryeri. The IUCN red list of threatened species 2012: e.T22715480A38218731. Downloaded on 27 May 2016

Boncoraglio G, Saino N (2007) Habitat structure and the evolution of bird song: a meta-analysis of the evidence for the acoustic adaptation hypothesis. Funct Ecol 21:134-142

Botero CA, Boogert NJ, Vehrencamp SL et al (2009) Climatic patterns predict the elaboration of song displays in mockingbirds. Curr Biol 19:1151-1155

Burnham KP, Anderson DR (2003) Model selection and multimodel inference: a practical informationtheoretic approach. Springer, New York

Byers BE (2011) Birdsong, migration and sexual selection: a skeptical view. Anim Behav 82:e1-e3

Byers BE (2015) Migration and song elaboration in wood-warblers (Geothlypis). Auk 132:167-179

Cardoso GC, Atwell JW (2012) On amplitude and frequency in birdsong: a reply to Zollinger et al. Anim Behav 84:e10-e15

Catchpole CK (1982) The evolution of bird sounds in relation to mating and spacing behavior. In: Kroodsma DE, Miller EH (eds) Acoustic communication in birds. Academic Press, London, pp 297-317

Collins S (2004) Vocal fighting and flirting: the functions of birdsong. In: Marler P, Slabbekorn H (eds) Nature's music: the science of birdsong. Elsevier, London, pp 39-79

Collins SA, de Kort SR, Perez-Tris J et al (2009) Migration strategy and divergent sexual selection on bird song. Proc R Soc B 276:585-590

Cosens SE, Falls JB (1984) A comparison of sound propagation and song frequency in temperate marsh and grassland habitats. Behav Ecol Sociobiol 15:161-170

Danner JE, Danner RM, Bonier F et al (2011) Female, but not male, tropical sparrows respond more strongly to the local song dialect: implications for population divergence. Am Nat 178:53-63

De Clercq EM, Leta S, Estrada-Pena A et al (2015) Species distribution modelling for Rhipicephalus microplus (Acari: Ixodidae) in Benin, west Africa: comparing datasets and modelling algorithms. Prev Vet Med 118:8-21

Edwards SV, Kingan SB, Calkins JD et al (2005) Speciation in birds: genes, geography, and sexual selection. Proc Natl Acad Sci USA 102:6550-6557

Eglington SM, Julliard R, Gargallo G et al (2015) Latitudinal gradients in the productivity of European migrant warblers have not shifted northwards during a period of climate change. Global Ecol Biogeogr 24:427-436

Ellers J, Slabbekoorn H (2003) Song divergence and male dispersal among bird populations: a spatially explicit model testing the role of vocal learning. Anim Behav 65:671-681

Ey E, Fischer J (2009) The "acoustic adaptation hypothesis"-a review of the evidence from birds, anurans and mammals. Bioacoustics 19:21-48

Fessl B, Hoi H (1996) The significance of a two part song in the moustached warbler (Acrocephalus melanopogon). Ethol Ecol Evol 8:265-278

Garris HW, Mitchell RJ, Fraser LH et al (2015) Forecasting climate change impacts on the distribution of wetland habitat in the Midwestern United states. Global Change Biol 21:766-776

Gordinho LD, Matheu E, Hasselquist D et al (2015) Song divergence between subspecies of reed bunting is more pronounced in singing styles under sexual selection. Anim Behav 107:221-231

Greig EI, Baldassarre DT, Webster MS et al (2015) Differential rates of phenotypic introgression are associated with male behavioral responses to multiple signals. Evolution 69:2602-2612

Gwitira I, Murwira A, Zengeya FM et al (2015) Modelled habitat suitability of a malaria causing vector (Anopheles arabiensis) relates well with human malaria incidences in Zimbabwe. Appl Geogr 60:130-138

Halupka L, Dyrcz A, Borowiec M et al (2008) Climate change affects breeding of reed warblers Acrocephalus scirpaceus. J Avian Biol 39:95-100

Hijmans RJ, Cameron SE, Parra JL et al (2005) Very high resolution interpolated climate surfaces for global land areas. Int J Climatol 25:1965-1978 
Hou Y (2014) Study on breeding ecology of Japanese marsh warbler (Megalurus pryeri) in Dandong Yalu River Estuary wetland. Master Thesis, Northeast Forestry University, Harbin

Hultsch H, Todt D (2004) Learning to sing. In: Marler P, Slabbekoorn H (eds) Nature's music: the science of birdsong. Elsevier, London, pp 80-107

Irwin DE (2000) Song variation in an avian ring species. Evolution 54:998-1010

Kaluthota C, Brinkman BE, Dos Santos EB et al (2016) Transcontinental latitudinal variation in song performance and complexity in house wrens (Troglodytes aedon). Proc R Soc B 283:20152765

Kleindorfer S, Evans C, Mihailova M et al (2013) When subspecies matter: resident superb fairy-wrens (Malurus cyaneus) distinguish the sex and subspecies of intruding birds. Emu 113:259

Kroodsma DE (1981) Geographical variation and functions of song types in warblers (Parulidae). Auk 98:743-751

Kroodsma DE (1999) Making ecological sense of song development in songbirds. In: Hauser MD, Konishi M (eds) The design of animal communication. MIT Press, Cambridge

Kroodsma DE (2004) The diversity and plasticity of birdsong. In: Marler P, Slabbekorn H (eds) Nature's music: the science of birdsong. Elsevier, London, pp 108-131

Lachlan RF, Verzijden MN, Bernard CS et al (2013) The progressive loss of syntactical structure in bird song along an island colonization chain. Curr Biol 23:1896-1901

Leedale AE, Collins SA, de Kort SR (2015) Blackcaps (Sylvia atricapilla) increase the whistle part of their song in response to simulated territorial intrusion. Ethology 121:403-409

Leitão A, Riebel K (2003) Are good ornaments bad armaments? Male chaffinch perception of songs with varying flourish length. Anim Behav 66:161-167

Li F, Wang Q (2006) Breeding biology of Japanese marsh warbler's sinensis subspecies. Acta Zool Sin 52:1162-1168

Linossier J, Courvoisier H, Aubin T (2015) The two parts of the blackcap song: acoustic analysis and male responses to playbacks. Behav Process 121:87-92

Louchart A (2008) Emergence of long distance bird migrations: a new model integrating global climate changes. Naturwissenschaften 95:1109-1119

Madge S (2006) Marsh grassbird (Megalurus pryeri). In: del Hoyo J, Elliott A, Sargatal J, Christie DA, de Juana E (eds) (2014) Handbook of the birds of the world alive. Lynx Edicions, Barcelona. http://www. hbw.com/node/58707. Retrieved 28 Nov 2015

Medina I, Francis CD (2012) Environmental variability and acoustic signals: a multi-level approach in songbirds. Biol Lett 8:928-931

Mortega KG, Flinks H, Helm B (2014) Behavioural response of a migratory songbird to geographic variation in song and morphology. Front Zool 11:85

Nakagawa S, Schielzeth H, O'Hara RB (2013) A general and simple method for obtaining $R^{2}$ from generalized linear mixed-effects models. Methods Ecol Evol 4:133-142

Podos J, Nowicki S (2004) Beaks, adaptation, and vocal evolution in Darwin's finches. Bioscience 54:501-510

Podos J, Warren PS (2007) The evolution of geographic variation in birdsong. Adv Stud Behav 37:403-458

Price T (2008) Speciation in birds. Roberts and Company Publishers, Greenwood Village

Qu WH, Li F, Sha JB et al (2011) Analyzing Japanese marsh warbler (Megalurus pryeri) song behavior in the breeding season. Zool Res 32:141-149

Quesnelle PE, Fahrig L, Lindsay KE (2013) Effects of habitat loss, habitat configuration and matrix composition on declining wetland species. Biol Conserv 160:200-208

Riebel K, Slater PJB (1998) Testing female chaffinch song preferences by operant conditioning. Anim Behav 56:1443-1453

Rolland J, Jiguet F, Jonsson KA et al (2014) Settling down of seasonal migrants promotes bird diversification. Proc R Soc B 281:20140473

Salewski V, Bruderer B (2007) The evolution of bird migration-a synthesis. Naturwissenschaften 94:268-279

Singh P, Price TD, Hartley I (2015) Causes of the latitudinal gradient in birdsong complexity assessed from geographical variation within two Himalayan warbler species. Ibis 157:511-527

Slabbekoorn H (2004) Habitat-dependent ambient noise: consistent spectral profiles in two African forest types. J Acoust Soc Am 116:3727

Slabbekoorn H, Smith TB (2002) Bird song, ecology and speciation. Philos Trans R Soc B 357:493-503

Slabbekoorn H, Jesse A, Bell DA (2003) Microgeographic song variation in island populations of the whitecrowned sparrow (Zonotrichia leucophrys nutalli): innovation through recombination. Behaviour 140:947-963

Slater P (1986) The cultural transmission of bird song. Trends Ecol Evol 1:94-97 
Virkkala R, Luoto M, Heikkinen RK et al (2005) Distribution patterns of boreal marshland birds: modelling the relationships to land cover and climate. J Biogeogr 32:1957-1970

Weir JT, Wheatcroft D (2011) A latitudinal gradient in rates of evolution of avian syllable diversity and song length. Proc R Soc B 278:1713-1720

Weir JT, Wheatcroft DJ, Price TD (2012) The role of ecological constraint in driving the evolution of avian song frequency across a latitudinal gradient. Evolution 66:2773-2783

Winker K (2000) Migration and speciation. Nature 404:36

Zhang YM (2011) Study on distribution and nest-site selection of marsh grassbird (Locustella pryeri) in China. Master Thesis, Northeast Forestry University, Harbin

Zink RM (2011) The evolution of avian migration. Biol J Linn Soc 104:237-250

Zollinger SA, Podos J, Nemeth E, Goller F, Brumm H (2012) On the relationship between, and measurement of, amplitude and frequency in birdsong. Anim Behav 84:e1-e9 